
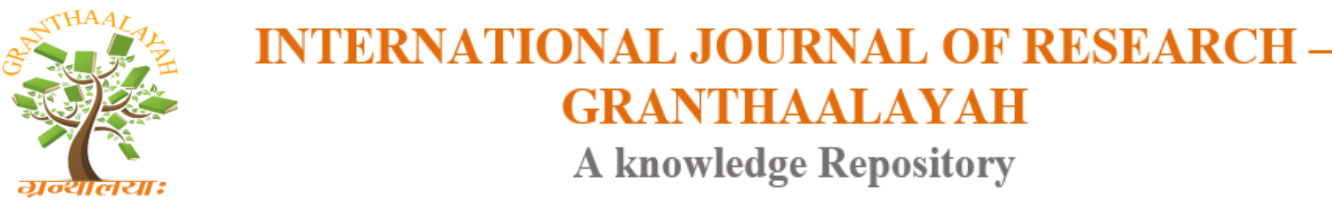

Science

\title{
IMPROVED BABOON ALGORITHM FOR MINIMIZATION OF REAL POWER LOSS
}

\author{
K.Lenin ${ }^{1}$, B.Ravindhranath Reddy ${ }^{2}$, M.Surya Kalavathi ${ }^{3}$ \\ ${ }^{1}$ Researcher, JNTU, Hyderabad 500085 India \\ ${ }^{2}$ Deputy Executive Engineer, JNTU, Hyderabad 500085 India \\ ${ }^{3}$ Professor in Department of Electrical and Electronics Engineering, JNTU, Hyderabad 500085 , \\ India
}

DOI: https://doi.org/10.29121/granthaalayah.v5.i1.2017.1690

\begin{abstract}
This paper projects Improved Baboon Algorithm (IBA) for solving the Reactive Power dispatch problem. The key feature in this problem is reduction of real power loss and to keep voltage profiles within limits. This algorithm is inspired from the tree climbing procedures of Baboons, where the Baboons look for the highest tree by climbing up from their positions. The simulation results expose amended performance of the IBA in solving an optimal reactive power dispatch problem. In order to evaluate up the performance of the proposed algorithm, it has been tested on Standard IEEE 30 bus system and compared to other stated algorithms. Simulation results show that IBA is better than other algorithms in reducing the real power loss and voltage profiles also within the limits.
\end{abstract}

Keywords: Improved Baboon Algorithm; Optimization; Metaheuristics; Optimal Reactive Power; Transmission Loss.

Cite This Article: K.Lenin, B.Ravindhranath Reddy, and M.Surya Kalavathi. (2017). "IMPROVED BABOON ALGORITHM FOR MINIMIZATION OF REAL POWER LOSS." International Journal of Research - Granthaalayah, 5(1), 33-42. https://doi.org/10.29121/granthaalayah.v5.i1.2017.1690.

\section{Introduction}

Power system consistency is related to safety, protection criterion and it refers to continuity of service, stability of frequency and specified voltage limits. The poor management of reactive power sources limits the active power transmission, which can cause uncontrollable lower level of voltage and tension fall down in the load buses. Optimal reactive power dispatch in power system is subject to uncertainties at least in the best case to improbability parameters given in the demand and the availability equivalent of shunt reactive power compensators. Optimal reactive power dispatch is a key factor for the operation and control of power systems, and should be 
carried out properly so that system reliability is not affected.The gradient method $[1,2]$, Newton method [3] and linear programming [4-7] suffer from the difficulty of handling the inequality constraints. Recently Global Optimization techniques such as genetic algorithms have been proposed to solve the reactive power flow problem [8-10]. In recent years, the problem of voltage stability and voltage collapse has become a major concern in power system planning and operation. The meta-heuristic algorithms have impressive features that differs them from the gradient based methods. In the field of structural optimization, genetic algorithms (GA) [11-12], particle swarm optimization (PSO) [13-14] and Ant colony optimization (ACO) [15-16] are the most admired algorithms used to solve various optimization problems.In this paper the Improved Baboon Algorithm (IBA) [17], is used to solve the optimal reactive power problem. Baboons are from Africa and Asia as shown in fig 1. They tends to live in the tropical locations most of the time. However, they are also found living in many dry areas. They are versatile and spend a great deal of time living in trees. Baboons consume a variety of different plants and leaves. They also spend time on land too though. This paper imitates the activity of baboon and algorithm has been framed to solve the reactive power problem. The performance of IBA has been evaluated in standard IEEE 30 bus test system and the simulation results shows that our proposed method outperforms all approaches investigated in this paper.

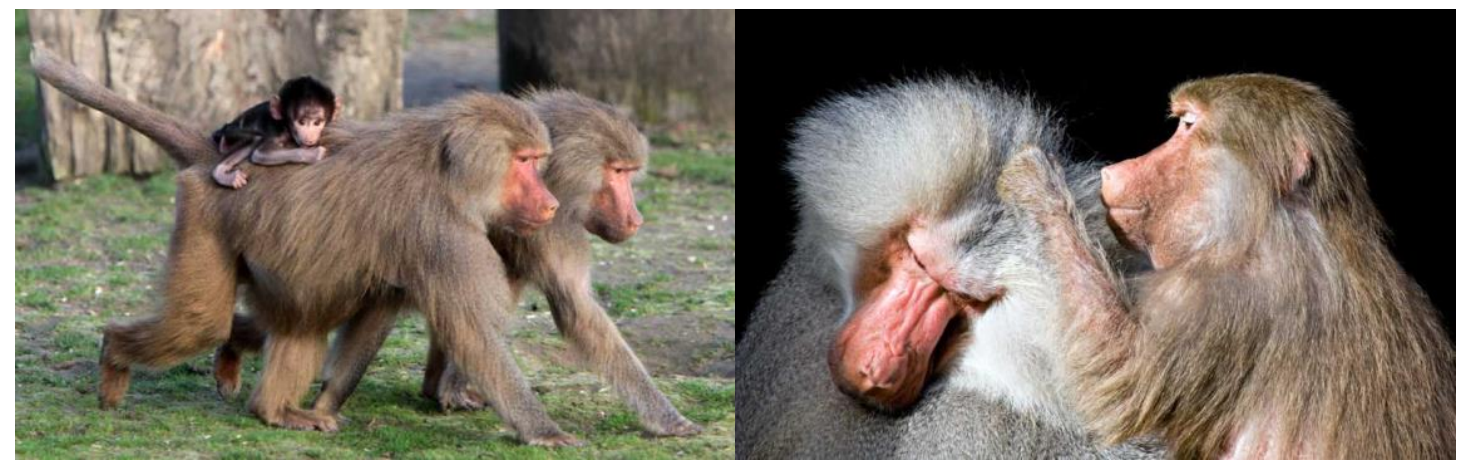

Figure 1: Baboon in forest

\section{Objective Function}

\subsection{Active Power Loss}

The objective of the reactive power dispatch problem is to minimize the active power loss and can be written in equations as follows:

$$
\mathrm{F}=P_{L}=\sum_{\mathrm{k} \in \mathrm{Nbr}} \mathrm{g}_{\mathrm{k}}\left(\mathrm{V}_{\mathrm{i}}^{2}+\mathrm{V}_{\mathrm{j}}^{2}-2 \mathrm{~V}_{\mathrm{i}} \mathrm{V}_{\mathrm{j}} \cos \theta_{\mathrm{ij}}\right)
$$

Where F- objective function, $\mathrm{P}_{\mathrm{L}}$ - power loss, $\mathrm{g}_{\mathrm{k}}$ - conductance of branch, $\mathrm{V}_{\mathrm{i}}$ and $\mathrm{V}_{\mathrm{j}}$ are voltages at buses $\mathrm{i}, \mathrm{j}, \mathrm{Nbr}$ - total number of transmission lines in power systems.

\subsection{Voltage Profile Improvement}

To minimize the voltage deviation in PQ buses, the objective function $(\mathrm{F})$ can be written as:

$$
\mathrm{F}=P_{L}+\omega_{\mathrm{V}} \times \mathrm{VD}
$$


Where VD - voltage deviation, $\omega_{v^{-}}$is a weighting factor of voltage deviation.

And the Voltage deviation given by:

Where Npq- number of load buses

$$
\mathrm{VD}=\sum_{\mathrm{i}=1}^{\mathrm{Npq}}\left|\mathrm{V}_{\mathrm{i}}-1\right|
$$

\subsection{Equality Constraint}

The equality constraint of the problem is indicated by the power balance equation as follows:

$$
\mathrm{P}_{\mathrm{G}}=\mathrm{P}_{\mathrm{D}}+\mathrm{P}_{\mathrm{L}}
$$

Where $\mathrm{P}_{\mathrm{G}^{-}}$total power generation, $\mathrm{P}_{\mathrm{D}}$ - total power demand.

\subsection{Inequality Constraints}

The inequality constraint implies the limits on components in the power system in addition to the limits created to make sure system security. Upper and lower bounds on the active power of slack bus $\left(\mathrm{P}_{\mathrm{g}}\right)$, and reactive power of generators $\left(\mathrm{Q}_{\mathrm{g}}\right)$ are written as follows:

$$
\begin{gathered}
\mathrm{P}_{\text {gslack }}^{\min } \leq \mathrm{P}_{\text {gslack }} \leq \mathrm{P}_{\text {gslack }}^{\max } \\
\mathrm{Q}_{\mathrm{gi}}^{\min } \leq \mathrm{Q}_{\mathrm{gi}} \leq \mathrm{Q}_{\mathrm{gi}}^{\max }, \mathrm{i} \in \mathrm{N}_{\mathrm{g}}
\end{gathered}
$$

Upper and lower bounds on the bus voltage magnitudes $\left(\mathrm{V}_{\mathrm{i}}\right)$ is given by:

$$
V_{i}^{\min } \leq V_{i} \leq V_{i}^{\max }, i \in N
$$

Upper and lower bounds on the transformers tap ratios $\left(\mathrm{T}_{\mathrm{i}}\right)$ is given by:

$$
\mathrm{T}_{\mathrm{i}}^{\min } \leq \mathrm{T}_{\mathrm{i}} \leq \mathrm{T}_{\mathrm{i}}^{\max }, \mathrm{i} \in \mathrm{N}_{\mathrm{T}}
$$

Upper and lower bounds on the compensators $\left(\mathrm{Q}_{\mathrm{c}}\right)$ is given by:

$$
\mathrm{Q}_{\mathrm{c}}^{\min } \leq \mathrm{Q}_{\mathrm{c}} \leq \mathrm{Q}_{\mathrm{C}}^{\max }, \mathrm{i} \in \mathrm{N}_{\mathrm{C}}
$$

Where $\mathrm{N}$ is the total number of buses, $\mathrm{N}_{\mathrm{g}}$ is the total number of generators, $\mathrm{N}_{\mathrm{T}}$ is the total number of Transformers, $\mathrm{N}_{\mathrm{c}}$ is the total number of shunt reactive compensators.

\section{Baboon Algorithm}

The Baboon algorithm (BA) is stimulated from the mountain climbing procedure of Baboons, where the Baboons look for the highest mountain by climbing up from their positions. When each Baboon gets to the top of the mountain, it looks about to find out whether there are higher mountains around or not. If yes, it will jump toward the mountain from the current position and 
then replicate the climbing until it reaches the top of the higher mountain. The BA is based on three main process namely as climb process, watch-jump process and somersault process. In following the Baboon algorithm, the proposed Improved Baboon algorithm (IBA) for optimal reactive power dispatch has been explained.

\subsection{Standard Baboon Algorithm}

Generally the Baboon algorithm [17] works as follows,

Step 1: Describe the population size of Baboons $(M)$, the climb number $\left(\mathrm{N}_{\mathrm{c}}\right)$, the objective function and the decision variables. Give the Input about system parameters and the boundaries of the decision variables.

The optimization problem can be defined as:

Minimization $\mathrm{f}(\mathrm{x})$

Subject to

$$
x_{j L} \leq x_{j} \leq x_{j U}
$$

Where $(j=1,2, . ., \mathrm{n}), x_{j L}$ and $x_{j U}$ lower and upper bounds of decision variables.

Step 2: Initialize a possible position for each Baboon, where the position of $i$ th Baboon is denoted as a vector with $n$ dimension:

$$
x_{i}=\left(x_{i 1}, x_{i 2}, \ldots, x_{i n}\right), i=1,2, \ldots, n
$$

Step 3: Climb procedure is a step by step procedure to change the Baboons' positions from the initial positions to new ones that makes an improvement in the objective function

The climb process can be explained in three stages:

Stage 1: Generate a vector randomly

Where

$$
\Delta x_{i}=\left(\Delta x_{i 1}, \Delta x_{i 2}, \ldots, \Delta x_{i n}\right), i=1,2, ., n
$$

$$
\Delta x_{i j}=\left\{\begin{array}{l}
+a p(+a)=0.5 \\
-a P(-a)=0.5
\end{array}\right.
$$

a- step length of climb process.

Stage 2: To calculate the simulated gradient of the objective function $f$ at point $x_{i}$

$$
\begin{aligned}
& f_{i j}^{\prime}=\frac{f\left(x_{i}+\Delta x_{i}\right)-f\left(x_{i}-\Delta x_{i}\right)}{2 \Delta x_{i j}}, j=1,2, ., n \\
& f_{i j}^{\prime}=\left(f_{i 1}^{\prime}\left(x_{i}\right), f_{i 2}^{\prime}\left(x_{i}\right), \ldots, f_{i n}^{\prime}\left(x_{i}\right)\right)
\end{aligned}
$$


Stage 3: Describe the parameter $y=\left(y_{1}, y_{2}, \ldots y_{n}\right)$ and it can be calculated as follows,

$$
y_{i}=x_{i j}+a \cdot \operatorname{sign}\left(f_{i j}^{\prime}\left(x_{i}\right)\right), j=1,2, \ldots, n
$$

If $y=\left(y_{1}, y_{2}, \ldots y_{n}\right)$ is feasible then $x_{i}$ is replaced by $y$, otherwise $x_{i}$ remains the same .

Stage 1to 3 are repeated until there is no considerable changes on the values of objective function or the climb number $\mathrm{N}_{\mathrm{c}}$ is reached.

Step 4: After the climb process, each Baboon arrives at its own mountaintop, therefore; each Baboon will look around to find a higher mountain. If a higher mountain is found, the Baboon will jump there (jump process). For this a parameter $b$ is defined as eyesight of the Baboon which is the maximal distance that the Baboon can watch.

The jump is based on two stages

Stage 1: A real number $y$ is generated randomly in the range of :

$$
y \in\left(x_{i j}-b, x_{i j}+b\right), j=1,2, ., n
$$

Stage 2: If $y$ is feasible and $f(y)$ is better than $f(x)$ for $i$ th Baboon $(f(y)>f(x))$, the position is updated; otherwise, Stage 1 is repeated.

Step 5: The climb process is repeated by considering $y$ as initial position.

Step 6: Somersault procedure: In this step, the Baboons find out new penetrating domain. Taking the centre of all the Baboons' positions as a pivot, each Baboon will somersault to a new position forward or backward in the direction of pointing at the pivot. Based on the new position, the Baboons will keep on climbing. The somersault procedure is as follows:

Stage 1: First a somersault interval $[c, d]$ is defined which the maximum distance that Baboons can somersault is. A real number $\alpha$ is generated randomly within the somersault interval.

Stage 2: Parameter y has been defined as follows,

$$
\begin{gathered}
y_{j}=x_{i j}+\alpha\left(P_{j}-x_{i j}\right) \\
P_{j}=\frac{1}{M} \sum_{i=1}^{M} x_{i j}, j=1,2, ., n
\end{gathered}
$$

Where $\mathrm{P}$ is somersault pivot.

Stage 3: If $y=\left(y_{1}, y_{2}, \ldots y_{n}\right)$ is feasible then $x_{i}$ is replaced by $y$, otherwise $x_{i}$ remains the same.

Step 7: Repeat steps 3-6 until the stopping criterion (maximum number of iteration) is met. 


\subsection{Improved Baboon Algorithm (IBA)}

To have a high performance search, an essential key is having an appropriate transaction between exploration and exploitation. Baboon Algorithm may fall into a local optimum early in a run on some optimization problems. In other words, the algorithm approaches the neighborhood of the global optimum but for some reasons it fails to converge to the global optimum. The stagnation could be due to the following reason:

Baboons don't share information and learning from each other, so this easily makes the algorithm to trap in the local optimum solution. Also the improvement in the position is in the range of $x_{i j}-b, x_{i j}+b$ and it has been done randomly. So the time process will be higher one to find better solution. In this IBA rather than going randomly by each Baboon based on local information, the information has been transferred and a common decision has been made by obtaining the information from other Baboons as below

$$
v_{m i}=x_{m i}+\Phi_{m i}\left(x_{m i}-x_{k i}\right)
$$

Where

$m=1,2, \ldots, M$

$i=1,2, \ldots, N$

$k=1,2, \ldots, M, k \neq i$

$\Phi_{m i}$ - Random number in the range of [-1,1], $i \& k$-are chosen randomly in the range of $\{1,2, \ldots, n\}$.

If the new position is better than previous position then the Baboon will jump otherwise the position remains unchanged. But the Baboon will try to improve the position by using the step. For this step a new counter $\left(N_{e}\right)$ and it is repeated until the count $\left(N_{e}\right)$ reached.

$$
\begin{aligned}
& \text { If } v_{m i}>x_{m i}^{\max } \Rightarrow v_{m i}=x_{m i}^{\max } \\
& \text { if } v_{m i}<x_{m i}^{\max } \Rightarrow v_{m i}=x_{m i}^{\min }
\end{aligned}
$$

IBA for solving reactive power dispatch problem,

- Initiate

- Scrutinize the data and identify constraint

- Reset the parameter

- Modernize iteration count up

- Climb technique

- Somersault technique

- Appraise the Baboon position using the new-fangled search operator

- If it meets stopping criterion process stop or go again to climb procedure.

- End 


\section{Simulation Results}

Validity of proposed IBA algorithm has been verified by testing in IEEE 30-bus, 41 branch system and it has 6 generator-bus voltage magnitudes, 4 transformer-tap settings, and 2 bus shunt reactive compensators. Bus 1 is taken as slack bus and 2, 5, 8, 11 and 13 are considered as PV generator buses and others are PQ load buses. Control variables limits are given in Table 1.

Table 1: Primary Variable Limits $(\mathrm{Pu})$

\begin{tabular}{|l|l|l|l|}
\hline Variables & Min. & Max. & category \\
\hline Generator Bus & 0.90 & 1.11 & Continuous \\
\hline Load Bus & 0.91 & 1.01 & Continuous \\
\hline Transformer-Tap & 0.92 & 1.01 & Discrete \\
\hline Shunt Reactive Compensator & -0.10 & 0.30 & Discrete \\
\hline
\end{tabular}

In Table 2 the power limits of generators buses are listed.

Table 2: Generators Power Limits

\begin{tabular}{|l|l|l|l|l|l|}
\hline Bus & Pg & Pgmin & Pgmax & Qgmin & Qmax \\
\hline 1 & 96.00 & 49 & 200 & 0 & 10 \\
\hline 2 & 79.00 & 18 & 79 & -40 & 50 \\
\hline 5 & 49.00 & 14 & 49 & -40 & 40 \\
\hline 8 & 21.00 & 11 & 31 & -10 & 40 \\
\hline 11 & 21.00 & 11 & 28 & -6 & 24 \\
\hline 13 & 21.00 & 11 & 39 & -6 & 24 \\
\hline
\end{tabular}

Table 3 shows the proposed IBA approach successfully kept the control variables within limits. Table 4 narrates about the performance of the proposed IBA algorithm. Fig 2 shows about the voltage deviations during the iterations and Table 5 list out the overall comparison of the results of optimal solution obtained by various methods.

Table 3: After optimization values of control variables

\begin{tabular}{|l|l|}
\hline Control Variables & IBA \\
\hline V1 & 1.0598 \\
\hline V2 & 1.0489 \\
\hline V5 & 1.0282 \\
\hline V8 & 1.0396 \\
\hline V11 & 1.0709 \\
\hline V13 & 1.0586 \\
\hline T4,12 & 0.00 \\
\hline T6,9 & 0.01 \\
\hline T6,10 & 0.90 \\
\hline T28,27 & 0.91 \\
\hline Q10 & 0.10 \\
\hline
\end{tabular}




\begin{tabular}{|l|l|}
\hline Q24 & 0.10 \\
\hline Real power loss & 4.2865 \\
\hline Voltage deviation & 0.9089 \\
\hline
\end{tabular}

Table 4: Performance of IBA algorithm

\begin{tabular}{|l|l|}
\hline Iterations & 29 \\
\hline Time taken $($ secs $)$ & 8.72 \\
\hline Real power loss & 4.2865 \\
\hline
\end{tabular}

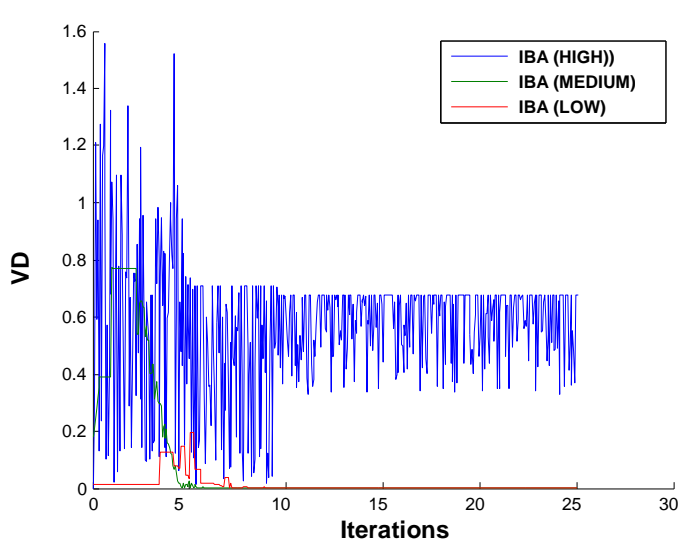

Figure 2: Voltage deviation (VD) characteristics

Table 5: Comparison of results

\begin{tabular}{|l|l|}
\hline Techniques & Real power loss (MW) \\
\hline SGA(Wu et al., 1998) [18] & 4.98 \\
\hline PSO(Zhao et al., 2005) [19] & 4.9262 \\
\hline \multicolumn{1}{|c|}{ LP(Mahadevan et al., 2010) [20] } & 5.988 \\
\hline EP(Mahadevan et al., 2010) [20] & 4.963 \\
\hline CGA(Mahadevan et al., 2010) [20] & 4.980 \\
\hline AGA(Mahadevan et al., 2010) [20] & 4.926 \\
\hline CLPSO(Mahadevan et al., 2010) [20] & 4.7208 \\
\hline HSA (Khazali et al., 2011) [21] & 4.7624 \\
\hline BB-BC (Sakthivel et al., 2013) [22] & 4.690 \\
\hline MCS(Tejaswini sharma et al.,2016) [23] & 4.87231 \\
\hline Proposed IBA & 4.2865 \\
\hline
\end{tabular}

\section{Conclusion}

In this Improved Baboon Algorithm (IBA) approach efficiently solved optimal reactive power problem. The performance of the proposed Improved Baboon Algorithm (IBA) has been demonstrated by testing it in IEEE 30-bus system. Simulation results shows that Real power loss has been considerably reduced and voltage profiles are within the specified limits. 


\section{References}

[1] O.Alsac,and B. Scott, "Optimal load flow with steady state security",IEEE Transaction. PAS 1973, pp. 745-751.

[2] Lee K Y ,Paru Y M , Oritz J L -A united approach to optimal real and reactive power dispatch , IEEE Transactions on power Apparatus and systems 1985: PAS-104 : 1147-1153

[3] A.Monticelli , M .V.F Pereira , and S. Granville, "Security constrained optimal power flow with post contingency corrective rescheduling", IEEE Transactions on Power Systems :PWRS-2, No. 1, pp.175-182.,1987.

[4] Deeb N ,Shahidehpur S.M ,Linear reactive power optimization in a large power network using the decomposition approach. IEEE Transactions on power system 1990: 5(2) : 428-435

[5] E. Hobson ,'Network consrained reactive power control using linear programming, ' IEEE Transactions on power systems PAS -99 (4), pp 868-877, 1980

[6] K.Y Lee ,Y.M Park, and J.L Oritz, "Fuel -cost optimization for both real and reactive power dispatches", IEE Proc; 131C,(3), pp.85-93.

[7] M.K. Mangoli, and K.Y. Lee, "Optimal real and reactive power control using linear programming”, Electr.Power Syst.Res, Vol.26, pp.1-10,1993.

[8] Berizzi.C.Bovo,M.Merlo,andM.Delfanti,(2012), "A GA approach to compare ORPF objective functions including secondary voltage regulation," Electric Power Systems Research, vol. 84, no. 1, pp. $187-194$.

[9] D. Devaraj, and B. Yeganarayana, "Genetic algorithm based optimal power flow for security enhancement", IEE proc-Generation.Transmission and. Distribution; 152, 6 November 2005.

[10] C.A. Canizares , A.C.Z.de Souza and V.H. Quintana , "Comparison of performance indices for detection of proximity to voltage collapse ," vol. 11. no.3 , pp.1441-1450, Aug 1996.

[11] Kaveh A, Kalatjari V. Genetic algorithm for discrete sizing optimal design of trusses using the force method, International Journal for Numerical Methods in Engineering, 55(2002) 55-72.

[12] Salajegheh E, Gholizadeh S. Optimum design of structures by an improved genetic algorithm using neural networks, Advances in Engineering Software, 36(2005) 757-67.

[13] Gholizadeh S, Salajegheh E. Optimal design of structures for time history loading by swarm intelligence and an advanced met model, Computer Methods in Applied Mechanics and Engineering, 198(2009) 2936-49.

[14] Kaveh A, Talatahari S. A hybrid particle swarm and ant colony optimization for design of truss structure, Asian Journal of Civil Engineering, 9(2008) 329-48.

[15] Camp CV, Bichon BJ. Design of space trusses using ant colony optimization, Journal of Structural Engineering, 130(2004) 741-51.

[16] Camp CV, Bichon BJ, Stovall SP. Design of steel frames using ant colony optimization, Journal of Structural Engineering, 131(2005) 369-79.

[17] R. Zhao, W. Tang, "Monkey Algorithm for Global Numerical Optimization", Journal of Uncertain Systems, Vol. 2, Issue 3, pp. 165-176, 2008.

[18] Wu.Q.H,Y.J.Cao,andJ.Y.Wen,(1998),"Optimal reactive power dispatch using an adaptive genetic algorithm”, Int.J.Elect.Power Energy Syst. Vol 20. Pp. 563-569.

[19] Zhao.B,C.X.Guo,andY.J.CAO,(2005),"Multiagent-based particle swarm optimization approach for optimal reactive power dispatch",IEEE Trans. Power Syst. Vol. 20, no. 2, pp. 1070-1078.

[20] Mahadevan.K,KannanP.S,(2010)“Comprehensive Learning Particle Swarm Optimization for Reactive Power Dispatch”, Applied Soft Computing, Vol. 10, No. 2, pp. 641-52.

[21] Khazali.A.H,M.Kalantar,(2011),“Optimal Reactive Power Dispatch based on Harmony Search Algorithm", Electrical Power and Energy Systems, Vol. 33, No. 3, pp. 684-692.

[22] Sakthivel.S,M.Gayathri,V.Manimozhi,(2013), "A Nature Inspired Optimization Algorithm for Reactive Power Control in a Power System", InternationalJournalofRecentTechnologyandEngineering,pp29-33Vol.2,Issue-1. 
[23] Tejaswini Sharma,Laxmi Srivastava,Shishir Dixit (2016). "Modified Cuckoo Search Algorithm For Optimal Reactive Power Dispatch", Proceedings of 38 th IRF International Conference,pp48. 20th March, 2016, Chennai, India, ISBN: 978-93-85973-76-5.

*Corresponding author.

E-mail address: gklenin@gmail.com 